Original Article

\title{
The effects of functional electrical stimulation on muscle tone and stiffness of stroke patients
}

\author{
SAng-Hyun Moon, PT, MD ${ }^{1)}$, Jung-Hyun Chol, PT, PhD²), Si-Eun Park, PT, $\mathrm{PhD}^{3)^{*}}$ \\ 1) Department of Physical Therapy, Dream Hospital, Republic of Korea \\ 2) Department of Physical Therapy, Institute for Elderly Health and Welfare, Namseoul University, \\ Republic of Korea \\ 3) Department of Physical Therapy, Pohang College: 60 Sindeok-ro, Heunghae-eup, Buk-gu, Pohang-si \\ 791-711, Republic of Korea
}

\begin{abstract}
Purpose] The purpose of this study was to determine the effects of functional electrical stimulation on muscle tone and stiffness in stroke patients. [Subjects and Methods] Ten patients who had suffered from stroke were recruited. The intervention was functional electrical stimulation on ankle dorsiflexor muscle (tibialis anterior). The duration of functional electrical stimulation was 30 minutes, 5 times a week for 6 weeks. The Myoton was used a measure the muscle tone and stiffness of the gastrocnemius muscle (medial and lateral part) on paretic side. [Results] In the assessment of muscle tone, medial and lateral part of gastrocnemius muscle showed differences before and after the experiment. Muscle stiffness of medial gastrocnemius muscle showed differences, and lateral gastrocnemius muscle showed differences before and after the experiment. The changes were greater in stiffness scores than muscle tone. [Conclusion] These results suggest that FES on ankle dorsiflexor muscle had a positive effect on muscle tone and stiffness of stroke patients.

Key words: Functional electrical stimulation, Muscle tone, Stroke
\end{abstract}

(This article was submitted Sep. 24, 2016, and was accepted Nov. 2, 2016)

\section{INTRODUCTION}

Muscle tone is defined as the resistance of muscle being passively lengthened ${ }^{1)}$. Abnormal muscle tone occurs in disorders of central nervous system and can affect up to two-thirds of patients with stroke ${ }^{2)}$. Especially, it is a common motor disorder following stroke, which may require rehabilitation ${ }^{3)}$. A hypertonus state leads to involuntary muscle contractions that interfere with the normal movements of the arms and legs, restrict the range of motion of joints, and lower extremity the functions of daily living, thereby restricting the functional recovery of patients ${ }^{4}$.

Yan and Hui-Chan reported that functional electrical stimulation (FES) may be able to normalize muscle tone in affected ankle plantar flexors ${ }^{5)}$. FES is a popular post-stroke gait rehabilitation intervention. FES is typically delivered to ankle dorsiflexors to correct foot drop during the swing phase ${ }^{6}$. FES is applied on the tibialis anterior muscle to enhance coordination capability during the gait cycle, and to increase the range of motion of the ankle joint and walking speed, thus improving gait quality ${ }^{7}$. FES appears to enhance balance control during walking and, thus, effectively management foot drop in stroke patients ${ }^{8}$. Cho et al. reported that treadmill training while FES was applied to the gluteus medius and tibialis anterior muscles increased lower limb muscle strength and improved balance and gait ${ }^{9)}$. Most previous studies assessed muscle strength and gait ability. However, few studies have assessed muscle tone and stiffness. Therefore, we investigated the influence of FES on muscle tone and stiffness in stroke patients.

Stroke survivors show significantly higher resistance torque and joint stiffness ${ }^{10)}$. Muscle stiffness, which is defined as a

*Corresponding author. Si-Eun Park (E-mail: si-yaa@hanmail.net)

(C2017 The Society of Physical Therapy Science. Published by IPEC Inc.

This is an open-access article distributed under the terms of the Creative Commons Attribution Non-Commercial No Derivatives (by-nc-nd) License $<$ http://creativecommons.org/licenses/by-nc-nd/4.0/>. 
change in passive tension per unit change in length, is an indication of a muscle's passive resistance to elongation ${ }^{11)}$. Ankle stiffness is associated with difficulty walking due to an asymmetric posture and a loss of balance and motor control ${ }^{12)}$. Limited ankle joint dorsiflexion is caused by calf muscle (gastrocnemius and soleus muscles) stiffness and soft contracture ${ }^{13)}$. Owing to an increase of muscle tension in the gastrocnemius muscle, stroke patients cannot actively control dorsiflexion, and foot drop tends to occur ${ }^{14}$.

In this study, we hypothesized that FES applied to the ankle dorsiflexor (tibialis anterior) may reduce muscle tone and stiffness of the gastrocnemis muscle (medial and lateral part) in stroke patients.

\section{SUBJECTS AND METHODS}

This study was conducted in D rehabilitation hospital (Seoul, South Korea). The study included 10 individuals who were diagnosed with stroke more than 6 months previously. Included subjects had no orthopedic diseases, and scored more than 24 points on the mini-mental state examination-Korean version (MMSK-K). We explained the purpose and methods of this study to the subjects, and only those who consented to participate were included in the study. The study protocol was approved by the local ethics committee of Namseoul University (1041479-201603-HR-005).

FES was applied to the dorsiflexor on the paretic side with the patient in a sitting position. Microstim (Medel GmbH, German) was used to provide FES. To enhance ankle dorsiflexion, the active electrode was attached to the origin of the tibialis anterior muscle. The reference electrode was attached at the insertion point of the tibialis anterior muscle. The stimulation intensity was increased until visible maximal contraction. The FES device was programmed for bipolar placement at a pulse rate of $35 \mathrm{~Hz}$, a pulse duration of $8 \mathrm{sec}$, and an off-pulse duration of $11 \mathrm{sec}$. The pulse amplitude was $250 \mu \mathrm{V}^{15}$ ). FES was applied for 30 minutes 5 times a week for 6 weeks.

A Myoton ${ }^{\circledR}$ PRO (MyotonAS, Estonia) was used to measure muscle tone and stiffness. Before measurement, the highest point of the muscle belly of the medial and lateral gastrocnemius muscles were marked with a skin marker. Muscle tone and stiffness were measured with the measurement device positioned vertically on the skin marker while the patient was relaxed and in a prone position. All measurements were made twice, and the averages measurements were used for data analysis.

\section{RESULTS}

Table 1 shows the general characteristics of the subjects. This study assessed the effect of FES on muscle tone and stiffness in stroke patients. The results are presented in Table 2. The muscle tone of the medial gastrocnemius muscle on the affected side showed a significant change a $1.20 \mathrm{~Hz}$ decrease from $15.44 \mathrm{~Hz}$ to $14.24 \mathrm{~Hz}(\mathrm{p}<0.05)$. The muscle tone of the lateral gastrocnemius muscle on the affected side showed a significant change an $0.86 \mathrm{~Hz}$ decrease from $14.29 \mathrm{~Hz}$ to $13.43 \mathrm{~Hz}$ $(\mathrm{p}<0.05)$. The muscle stiffness of the medial gastrocnemius muscle on the affected side showed a significant change a 16.30 $\mathrm{N} / \mathrm{m}$ decrease from $268.50 \mathrm{~N} / \mathrm{m}$ to $252.30 \mathrm{~N} / \mathrm{m}(\mathrm{p}<0.01)$. The muscle stiffness of the lateral gastrocnemius muscle on the affected side showed a significant change a $14.3 \mathrm{~N} / \mathrm{m}$ decrease from $271.90 \mathrm{~N} / \mathrm{m}$ to $257.60 \mathrm{~N} / \mathrm{m}$ ( $\mathrm{p}=0.01)$.

Table 1. General characteristics of subjects

\begin{tabular}{lc}
\hline Gender & Male $=6 /$ Female $=4$ \\
Age $($ years $)$ & $57.5 \pm 7.8$ \\
Weight $(\mathrm{kg})$ & $70.8 \pm 5.2$ \\
Height $(\mathrm{cm})$ & $166.4 \pm 6.8$ \\
Post-stroke duration (months) & $57.5 \pm 7.8$ \\
Paretic side & Left $=5 /$ Right $=5$ \\
K-MMSE & $29.3 \pm 1.1$ \\
\hline Mean \pm SD & \\
K-MMSE: Korean version of Mini-Mental State Examination
\end{tabular}

Table 2. Muscle tone and stiffness of gastrocnemius muscle on affected side

\begin{tabular}{lcccc}
\hline \multirow{2}{*}{ Muscle } & \multicolumn{2}{c}{ Muscle tone $(\mathrm{Hz})$} & \multicolumn{2}{c}{ Stiffness $(\mathrm{N} / \mathrm{m})$} \\
\cline { 2 - 5 } & Before & After & Before & After \\
\hline Medial gastrocnemius & $15.4 \pm 1.9$ & $14.2 \pm 1.7^{*}$ & $268.5 \pm 21.0$ & $252.2 \pm 21.1^{* *}$ \\
Lateral gastrocnemius & $14.2 \pm 1.1$ & $13.4 \pm 1.5^{*}$ & $271.9 \pm 29.0$ & $257.6 \pm 26.5^{*}$ \\
\hline Mean \pm SD & & & & \\
${ }^{*} p<0.05,{ }^{* *} \mathrm{p}<0.01$ & & & &
\end{tabular}




\section{DISCUSSION}

This study examined the influence of FES training on muscle tone and stiffness in stroke patients. Spasticity frequently interferes motor function in stroke, spinal cord injury, and cerebral palsy patients. During neurological rehabilitation, control of spasticity is often a significant problem ${ }^{16}$. Spasticity in the foot of stroke patients was associated with difficulty during walking due to an asymmetric posture and a loss of balance and motor control ${ }^{13)}$. Deterioration of ankle joint motion, such as a reduced range of motion and tight heel cords can result in a clumsy gait and excessive energy expenditure ${ }^{17)}$. In particular, the ankle plantar flexor muscles play an important role during gait ${ }^{6)}$. Spasticity of the calf muscles disrupts walking in stroke patients. Therefore, muscle tone and stiffness of the ankle plantar flexor are a critical concern during treatment of stroke patients $^{18)}$.

FES has been widely used to treat patients with central nervous system lesions in order to improve motor control ${ }^{7)}$. FES increases the activity of the cerebral sensory-motor cortex in stroke patients and has an effect on functional movement, and it has a positive effect on motor learning and improves the effectiveness of treatment ${ }^{19}$ ). In more than 40 years of FES research, principles for safe stimulation of neuromuscular tissue have been established, and methods for modulating the strength of electrically induced muscle contractions have been discovered ${ }^{20)}$.

According to our results, both muscle tone and stiffness of the gastrocnemius muscle significantly decreased after 6 weeks of intervention. The changes in stiffness were greater than the change in tone. The mechanical properties of a muscle are typically expressed as stiffness, which is related to the amount, type, temperature, and organization of structures such as muscle, elastin, proteoglycans and water. Stroke patients showed higher resistance torque and joint stiffness ${ }^{10)}$. In patients with spasticity, the passive mechanical properties of muscle are to some extent responsible for impaired gait patterns ${ }^{21)}$. Spasticity is characterized by an increase in muscle tone, with accompanying hyperactivity in muscle stretch reflexes, abnormally high velocity-dependent resistance to passive muscle stretch, and lack of coordination ${ }^{22)}$. Therefore, muscle tone and stiffness are associated with spasticity.

Burridge et al. reported that spasticity reduction is achievable with the use of FES, and that the treatment does not cause muscle weakness or paralysis. They also claimed that patient quality of life and range of motion are improved following use of an FES system ${ }^{23)}$. Yan et al. reported that fifteen sessions of FES, greatly reduced muscle spasticity and increased ankle dorsiflexion torque in survivors of acute stroke. They also revealed that FES improved motor and walking ability in acute stroke patients and that more subjects were able to return to home following the procedure ${ }^{5)}$. These results are consistent with those of the present study, which show that FES positively influences muscle tone and stiffness.

Kesar et al. suggested that FES affects the control of gait pattern by stimulating specific muscle contraction rather than by production of force ${ }^{6}$. Furthermore, Kim et al. reported that stroke patients' gait patterns were more stable after 8 weeks of FES intervention ${ }^{15)}$. This means that FES positively affects gait.

Bakhtiary et al. reported that therapy combining electrical stimulation and the Bobath inhibitory technique reduced plantar flexor spasticity in stroke patients ${ }^{24}$. Also, Sabut et al. showed that the clinical implementation of FES together with a conventional rehabilitation program may reduce spasticity, improve voluntary joint movement and muscle strength, and improve functional recovery in stroke patients ${ }^{25}$. Therefore, additional research is necessary regarding diverse factors affected by FES.

This study included a limited number of subjects and did not include a control group. Therefore, further studies should be performed that include a larger number of subjects. However, this study may suggest only the potential of the FES can contribute to the rehabilitation of stroke patients.

\section{ACKNOWLEDGEMENT}

This research was conducted by the research grant of Sehan University in 2017.

\section{REFERENCES}

1) Gordon J: Disorders of motor control. In: Ada L, Canning C (eds.), Key issues in neurological Physiotherapy. London: Heinemann, 1990 , p 35.

2) Gregson JM, Leathley MJ, Moore AP, et al.: Reliability of measurements of muscle tone and muscle power in stroke patients. Age Ageing, 2000, 29: 223-228. [Medline] [CrossRef]

3) Blackburn M, van Vliet P, Mockett SP: Reliability of measurements obtained with the modified Ashworth scale in the lower extremities of people with stroke. Phys Ther, 2002, 82: 25-34. [Medline]

4) Welmer AK, von Arbin M, Widén Holmqvist L, et al.: Spasticity and its association with functioning and health-related quality of life 18 months after stroke. Cerebrovasc Dis, 2006, 21: 247-253. [Medline] [CrossRef]

5) Yan T, Hui-Chan CW, Li LS: Functional electrical stimulation improves motor recovery of the lower extremity and walking ability of subjects with first acute stroke: a randomized placebo-controlled trial. Stroke, 2005, 36: 80-85. [Medline] [CrossRef] 
6) Kesar TM, Perumal R, Reisman DS, et al.: Functional electrical stimulation of ankle plantarflexor and dorsiflexor muscles: effects on poststroke gait. Stroke, 2009, 40: 3821-3827. [Medline] [CrossRef]

7) Rushton DN: Functional electrical stimulation and rehabilitation—an hypothesis. Med Eng Phys, 2003, 25: 75-78. [Medline] [CrossRef]

8) Ring H, Treger I, Gruendlinger L, et al.: Neuroprosthesis for footdrop compared with an ankle-foot orthosis: effects on postural control during walking. J Stroke Cerebrovasc Dis, 2009, 18: 41-47. [Medline] [CrossRef]

9) Cho MK, Kim JH, Chung Y, et al.: Treadmill gait training combined with functional electrical stimulation on hip abductor and ankle dorsiflexor muscles for chronic hemiparesis. Gait Posture, 2015, 42: 73-78. [Medline] [CrossRef]

10) Gao F, Ren Y, Roth EJ, et al.: Effects of repeated ankle stretching on calf muscle-tendon and ankle biomechanical properties in stroke survivors. Clin Biomech (Bristol, Avon), 2011, 26: 516-522. [Medline] [CrossRef]

11) Kim IC, Lee BH: Effects of augmented reality with functional electrical stimulation on muscle strength, balance and gait of stroke patients. J Phys Ther Sci, 2012, 24: 755-762. [CrossRef]

12) Caillet F, Mertens P, Rabaséda S, et al.: [Three dimensional gait analysis and controlling spastic foot on stroke patients]. Ann Readapt Med Phys, 2003, 46: 119-131. [Medline] [CrossRef]

13) Lardner R: Stretching and flexibility, its importance in rehabilitation. J Bodyw Mov Ther, 2001, 5: 254-263. [CrossRef]

14) Park YH, Kim YM, Lee BH: An ankle proprioceptive control program improves balance, gait ability of chronic stroke patients. J Phys Ther Sci, 2013, 25: 1321-1324. [Medline] [CrossRef]

15) Kim MY, Kim JH, Lee JU, et al.: The effects of functional electrical stimulation on balance of stroke patients in the standing posture. J Phys Ther Sci, 2012, 24: 77-81. [CrossRef]

16) Tsai KH, Yeh CY, Chang HY, et al.: Effects of a single session of prolonged muscle stretch on spastic muscle of stroke patients. Proc Natl Sci Counc Repub China B, 2001, 25: 76-81. [Medline]

17) Perry J: Gait analysis: normal and pathological function. SLACK, 1992.

18) Dones I, Nazzi V, Broggi G: The guidelines for the diagnosis and treatment of spasticity. J Neurosurg Sci, 2006, 50: 101-105. [Medline]

19) Hara Y: Neurorehabilitation with new functional electrical stimulation for hemiparetic upper extremity in stroke patients. J Nippon Med Sch, 2008, 75: 4-14. [Medline] [CrossRef]

20) Peckham PH, Knutson JS: Functional electrical stimulation for neuromuscular applications. Annu Rev Biomed Eng, 2005, 7: 327-360. [Medline] [CrossRef]

21) Bressel E, McNair PJ: The effect of prolonged static and cyclic stretching on ankle joint stiffness, torque relaxation, and gait in people with stroke. Phys Ther, 2002, 82: 880-887. [Medline]

22) Allison SC, Abraham LD: Correlation of quantitative measures with the modified Ashworth scale in the assessment of plantar flexor spasticity in patients with traumatic brain injury. J Neurol, 1995, 242: 699-706. [Medline] [CrossRef]

23) Burridge JH, Ladouceur M: Clinical and therapeutic applications of neuromuscular stimulation: a review of current use and speculation into future developments. Neuromodulation, 2001, 4: 147-154. [Medline] [CrossRef]

24) Bakhtiary AH, Fatemy E: Does electrical stimulation reduce spasticity after stroke? A randomized controlled study. Clin Rehabil, 2008, 22: 418-425. [Medline] [CrossRef]

25) Sabut SK, Sikdar C, Kumar R, et al.: Functional electrical stimulation of dorsiflexor muscle: effects on dorsiflexor strength, plantarflexor spasticity, and motor recovery in stroke patients. NeuroRehabilitation, 2011, 29: 393-400. [Medline] 